\title{
OLHOS DA RIBEIRA: PROPOSTA INTEGRADA DE REQUALIFICAÇÃO PARA O BAIRRO DA RIBEIRA
}

\section{OJOS DE LA RIBEIRA: PROPUESTA INTEGRADA DE RECALIFICACIÓN PARA EL BARRIO DE LA RIBEIRA}

\author{
RIBEIRA'S EYES: INTEGRATED PROPOSAL FOR THE REHABILITATION OF THE RIBEIRA \\ NEIGHBORHOOD
}

\section{ATAÍDE, RUTH MARIA DA COSTA}

Professora Doutora, PPGAU-UFRN, rataide57@gmail.com

\section{MARTINO, NICHOLAS SARAIVA}

Estudante de mestrado em arquitetura e urbanismo, PPGAU-UFRN. nicholas.martino@estudante.abea.arq.br

\section{SCHEER, MARCELA LORENA FARKAT}

Estudante de mestrado em arquitetura e urbanismo,PPGAU-UFRN. marcela.scheer@ufrn.abea.arq.br

\section{SOUZA, DMETRYUS TARGINO MARQUES DE}

Estudante de graduação em arquitetura e urbanismo, UFRN, dmetryus.targino@ufrn.abea.arq.br

\section{INTRODUÇÃO}

Marcado por abrigar historicamente atividades culturais, comerciais e de serviços, e, por isso, ser lugar de forte dinamismo econômico até meados do século XX, o bairro Ribeira carrega, hoje, um estigma de abandono em virtude da redução e mudanças locacionais de investimentos nas últimas décadas, o que resultou em uma retração econômica. A Av. Duque de Caxias, eixo de conexão norte-sul do bairro com a cidade, concentra atividades predominantemente institucionais, carecendo da presença de outras atividades que contribuam para ampliar sua vitalidade também em horários variados do dia.

Desde a promulgação do Estatuto da Cidade - Lei 10.257/01 (BRASIL, 2001), tem havido esforços institucionais no sentido de promover a reabilitação e preservação das áreas de valor patrimonial localizadas nos centros históricos das cidades brasileiras. O cenário de abandono desses espaços, associado à precariedade do ambiente construído, com imóveis ociosos e o crescente déficit habitacional tem orientado as ações do Ministério das Cidades, no sentido de realçar a importância da adoção de estratégias que priorizem a recuperação de áreas degradadas como forma de solucionar o problema da moradia. Entretanto, como afirma Raquel Rolnik (2006), essas estratégias não têm conseguido dialogar com as demandas oriundas dos mercados de menor renda.

O bairro da Ribeira, localizado em Natal/RN, tem sido lócus de diversas iniciativas de reabilitação, seja por meio de projetos de cooperação institucional como os mais recentes Programa ReHabitar (SEMURB/NATAL, 2007), Plano de Reabilitação de Áreas Urbanas Centrais - PRAC/Ribeira (TINÔCO; SOBRINHA; TRIGUEIRO, 2008) e PAC cidades históricas (em curso), ou iniciativas normativas associadas a intervenções nos espaços públicos e privados como as duas edições da Operação Urbana Ribeira (OUR), que observaram determinações do Plano Diretor do município de 1994.

Em 2017, o Banco Interamericano de Desenvolvimento (BID) lançou a primeira edição do concurso nacional de ideias UrbanLab Brasil para a revitalização de parte do bairro da Ribeira, desenvolvido em três etapas, tendo como proposta vencedora a que se traduz no presente artigo denominada "Olhos da Ribeira". 
A proposta inclui estratégias urbanísticas, arquitetônicas, tecnológicas e de gestão as quais, no esforço de preencher algumas lacunas deixadas pelas intervenções anteriores, estão estruturadas em três eixos: desenvolvimento, vitalidade e memória. Entre essas estratégias, destaca-se a criação de uma plataforma online que pode viabilizar a participação da população nos processos de tomada de decisão, iniciativas de crowdfunding como meio de financiamento das obras e o incentivo ao urbanismo tático e à apropriação dos espaços públicos do bairro pelas pessoas, através de um sistema de pontos que possibilita a integração entre espaço urbano, população e gestão pública.

O artigo está estruturado em cinco sessões: (1) breve análise das ações normativas e tentativas anteriores de projetos para requalificação do bairro e explanação geral da proposta, (2) ações de mobilidade e infraestrutura resultantes desta análise, (3) propostas para requalificação dos espaços livres públicos, (4) ideias de formas de ocupação do espaço edificado que incentivem a vitalidade urbana do lugar e (5) mecanismos de gestão que auxiliam na viabilização econômica e administrativa desses projetos.

\section{DESENVOLVIMENTO DA PROPOSTA}

\subsection{ANTECEDENTES}

Até meados do século $\mathrm{XX}$, os centros históricos das cidades constituíam áreas multifuncionais, cuja multiplicidade de atividades e personagens, que se entrelaçam numa relação amigável com a rua, explicam muito dos encantamentos exercidos por essas áreas, criando motivações para os atuais projetos de reabilitação. Nesse sentido, pensar nas diversas formas de adensamento que podem ser produzidas nessas áreas é imprescindível para que novas formas de sociabilidade, que resgatem e reforcem a vitalidade desses centros, possam se reproduzir.

Em Natal, o bairro Ribeira é exemplar no que se refere às dificuldades de comunicação entre os agentes públicos e privados, que se adicionam a falta de atendimento e as necessidades da população, fatores que ampliam o estigma de abandono. Além disso, Heitor Silva (2002) aponta para a ineficiência da gestão municipal e a falta de marketing para divulgação e valorização da área, bem como a efetivação das propostas advindas da primeira Lei de Operação Urbana (1997). Silva (2002) ainda observa que os indícios de revitalização urbana do bairro limitaram-se à dimensão econômica, sem que, para atrair capitais, as ações urbanas fossem associadas aos correspondentes mecanismos de gestão e controle.

Entretanto, as diversas ações legais, desde a instituição das Zonas Especiais e Preservação Histórica (ZEPH), em 1990, e os planos e projetos elaborados ao longo das três últimas décadas demonstram que não faltaram estudos e esforços buscando a recuperação dos espaços degradados do bairro mais recente. Nesse sentido, o objeto de discussão do presente artigo é resultado de um concurso universitário de ideias promovido pelo Banco Interamericano de Desenvolvimento (BID) em parceria com a Caixa Econômica Federal (CEF), a Prefeitura Municipal de Natal e o Ministério das Cidades, lançado em maio de 2017, denominado BID UrbanLab Brasil.

A proposta vencedora, intitulada Olhos da Ribeira, apresenta um plano de ações urbanísticas e administrativas pautado em três eixos: desenvolvimento, vitalidade e memória. Como forma de contemplar os referidos eixos, o plano dividiu-se em ações de infraestrutura (que viabilize o adensamento proposto e atraia o investimento em novos usos para o bairro - desenvolvimento); ações nos espaços livres, como forma de enfatizar o uso das ruas pelas pessoas (vitalidade) e ações no espaço edificado, percebendo a importância das edificações de valor patrimonial, bem como nas novas edificações que possam atrair novos moradores, investidores e trabalhadores e reavivar seu caráter de urbanidade (memória). Ao final, os mecanismos de financiamento e gestão são definidos como meio para viabilizar esse conjunto de ações (Figura 1).

A proposta Olhos da Ribeira busca, ainda, integrar ferramentas de tecnologia da informação, a fim de facilitar a comunicação entre os interessados no desenvolvimento urbano do bairro, bem como sua divulgação e incentivo à construção coletiva do projeto. Assim, esse projeto tem como diferencial a criação de uma plataforma online participativa onde o usuário do bairro possa opinar, sugerir e acompanhar o emprego dos investimentos públicos e privados (Figura 2). 
Figura 1: Plano Geral de Intervenções.

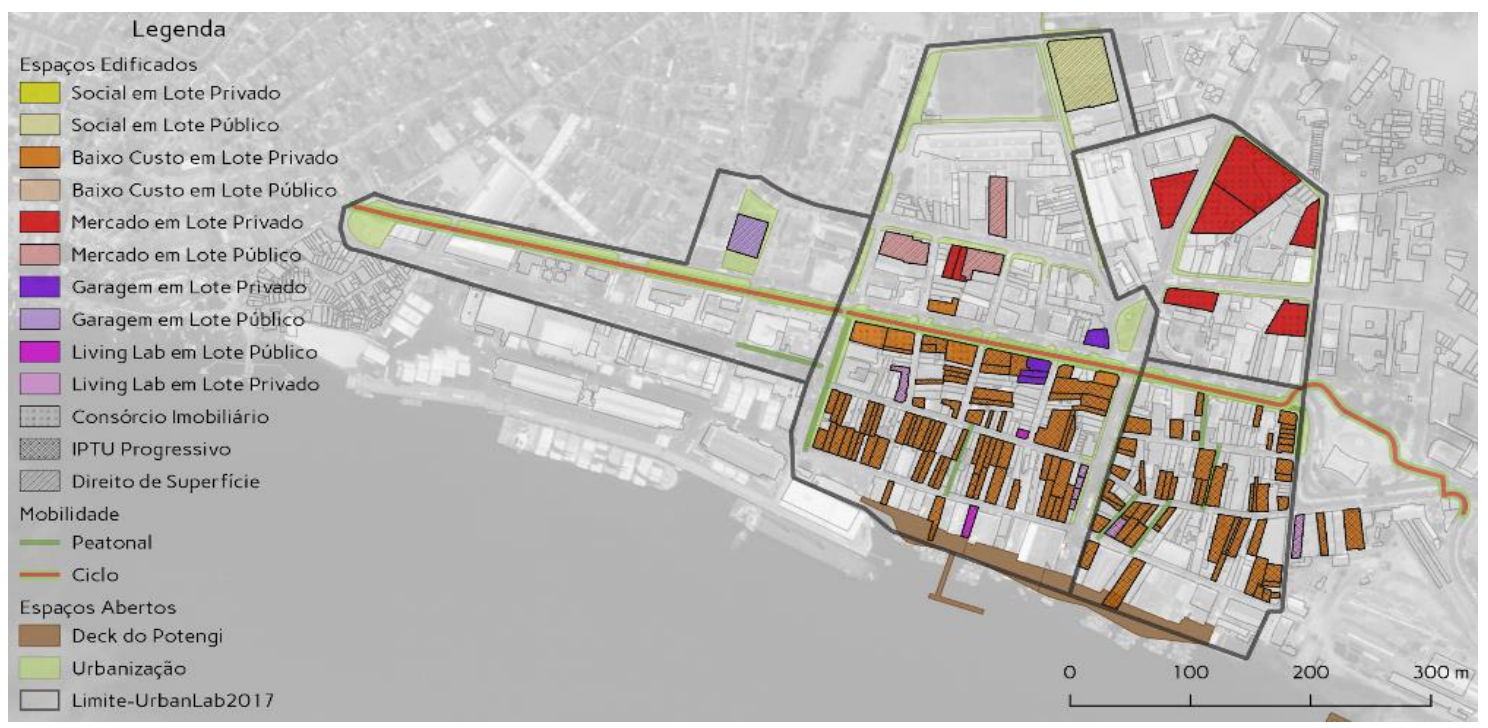

Fonte: Acervo dos autores (2018).

Figura 2: Interface do usuário na plataforma móvel.
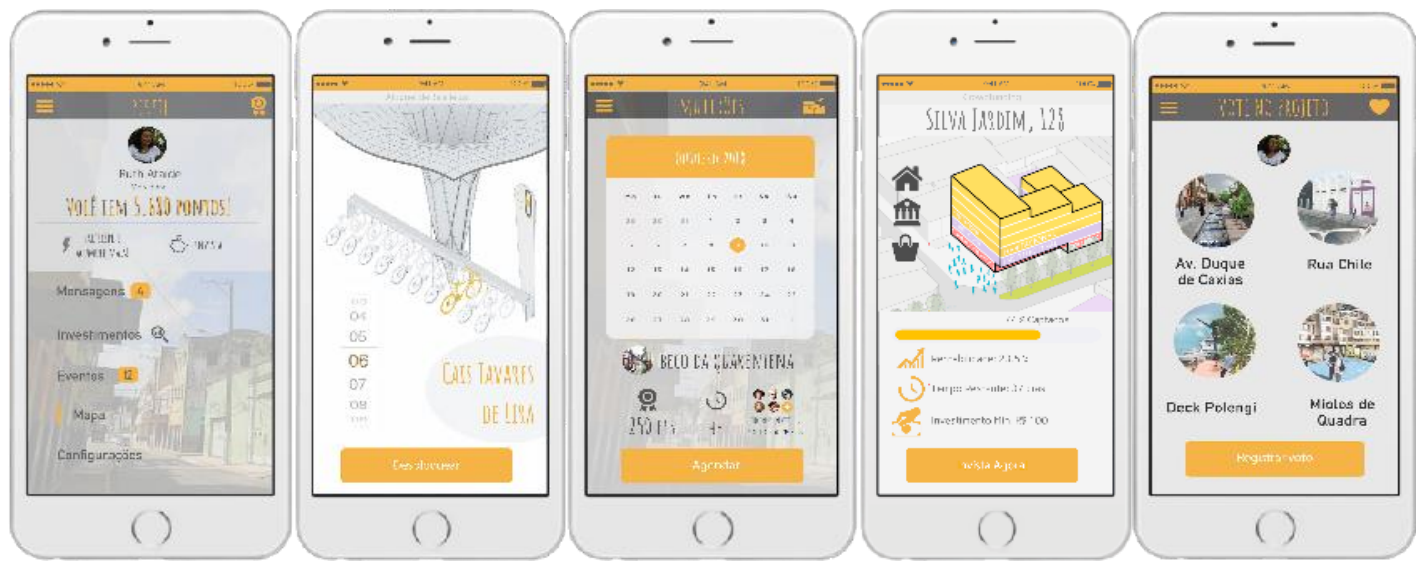

Fonte: Acervo dos autores (2018).

Com essa plataforma, os usuários do bairro podem ter um canal de participação na vida pública local e de comunicação entre agentes públicos, privados e os demais interessados no desenvolvimento urbano da Ribeira. A plataforma auxilia os usuários a se locomoverem pelo bairro, a participarem de eventos, a investirem em projetos privados e a votarem no destino dos recursos públicos destinados ao local. Esse tipo de estratégia almeja produzir uma gestão mais transparente e democrática, estimulando a participação direta e ativa dos usuários.

\subsection{AÇÕES EM INFRAESTRUTURA}

Quanto às ações em infraestrutura, a primeira identificada pauta-se na drenagem. Identifica-se que o sistema é bem distribuído, porém carece de manutenção. Com base nas ações do Grupo Coopere (2013)1, propõese desobstruir o canal de drenagem central e as redes associadas, recuperar galerias e bueiros, além de abrir valas de infiltração que auxiliem o escoamento, já que a proposta busca uma integração entre os sistemas de drenagem e a infraestrutura verde compatíveis com os níveis de adensamento.

Associado às ações físicas, o plano de mobilidade se orienta pela priorização dos modais ativos de transporte. Assim, propõe-se a criação de um novo binário - envolvendo as Avenidas Duque de Caxias e reforçando os modais já existentes - com a finalidade de reservar uma das faixas da referida Avenida para o passeio público, com um circuito integrado ao plano cicloviário do município (Figura 3). 
Figura 3: Plano de mobilidade

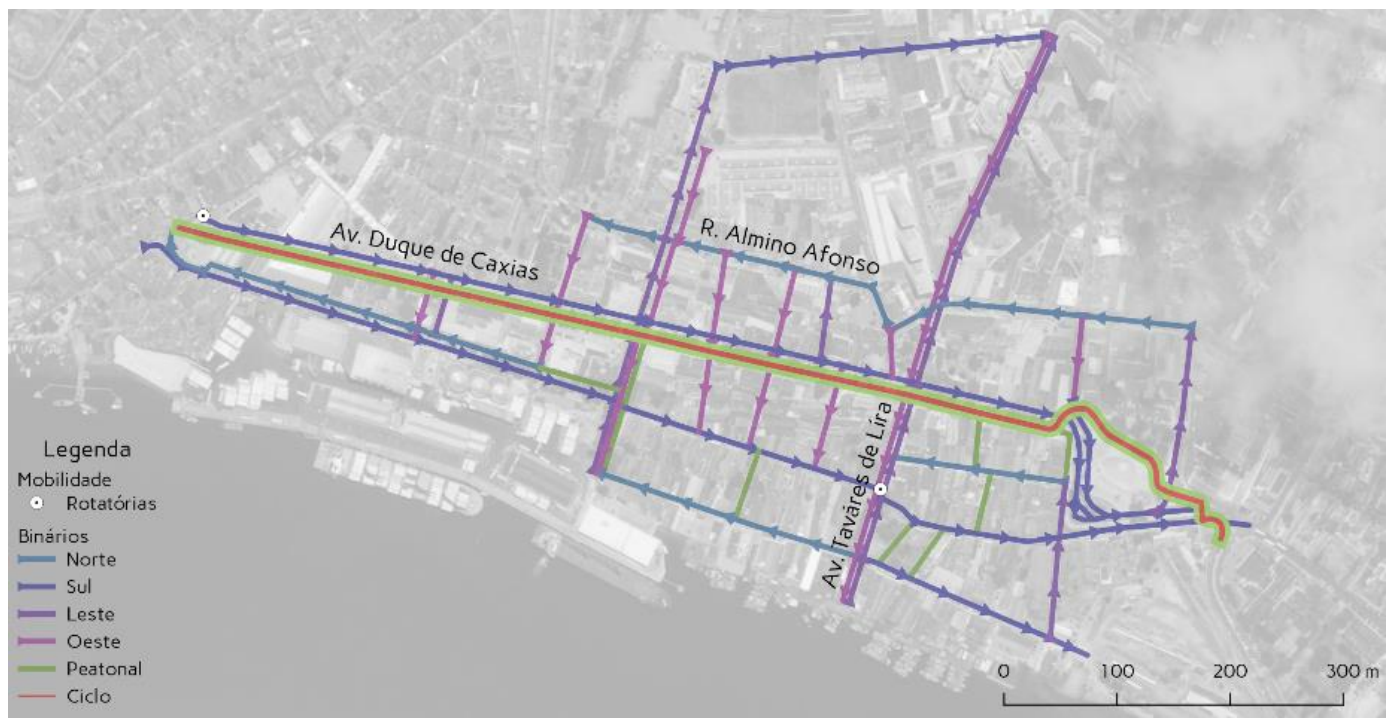

Fonte: Acervo dos autores (2018).

Nas faixas destinadas ao passeio, propõe-se o estímulo à instalação de usos diversos de modo a promover maior urbanidade e vitalidade nas vias, onde algumas calçadas, hoje, estão cercadas por muros de algumas edificações institucionais. Nesse sentido, reservam-se faixas para ônibus, mantendo-se alguns bolsões de estacionamento, articulados a um plano de parquímetros que pode contribuir para rentabilizar o uso do espaço público, proporcionando algum retorno financeiro para a área (Figuras 4 e 5). Nos passeios também deverão ser instalados pontos de aluguel de bicicleta, que estimulem a utilização do modal. $\mathrm{O}$ aplicativo integraria 0 acesso e o pagamento dos parquímetros e aluguel de bicicletas.

Figuras 4 e 5:Possibilidades de desenho para Av. Duque de Caxias.

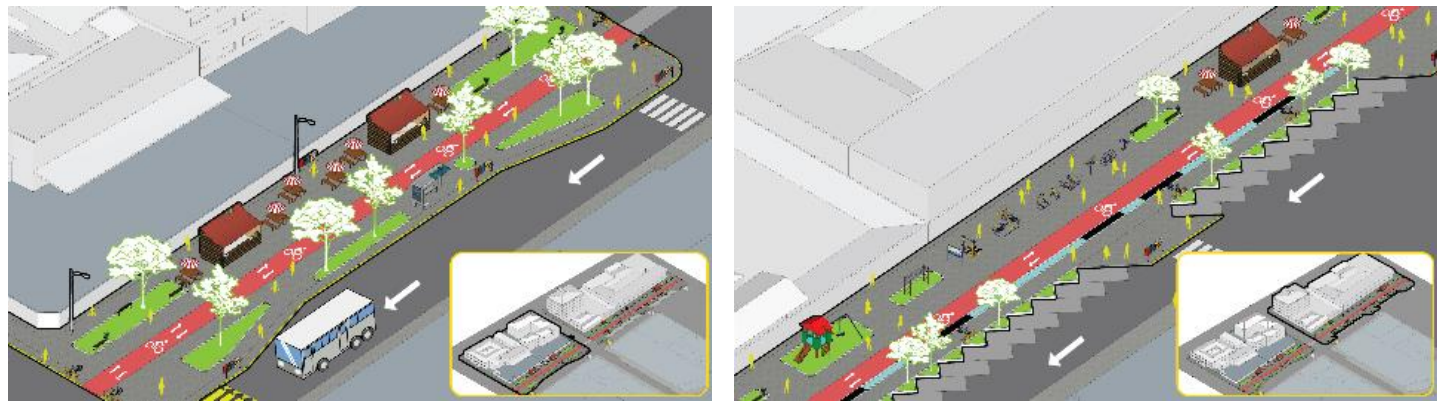

Fonte: Acervo dos autores (2018).

O plano prevê a abertura de novas conexões, que realcem o vínculo do bairro e da cidade com o Rio Potengi, por meio de uma rota hidroviária, conectando o bairro com a Redinha e à Região Norte, especificamente.

\subsection{AÇÕES NOS ESPAÇOS LIVRES}

As intervenções nos espaços livres buscam, prioritariamente, coletivizar a frente do rio, por meio de um deck público o qual, com acesso a janelas para o Rio Potengi a partir da Rua Chile, possa fomentar o potencial paisagístico da área e resgatar esse elemento como bem patrimonial da cidade. $O$ reconhecimento da importância da pesca artesanal também se faz presente no plano, que contempla ações de melhoria urbanística nos espaços que dão suporte a essa importante atividade na dinâmica econômica atual do bairro.

Com o propósito de incentivar a economia colaborativa, o plano também incorpora estratégias de urbanismo tático para requalificar os becos e travessas, podendo ser aplicadas em outras vias locais. Essas estratégias se apoiam em soluções rápidas e acessíveis à população, como a confecção de mobiliário de fácil execução e a reutilização de materiais e intervenções de arte urbana - como o grafite, que pode contribuir para a 
requalificação desses espaços (muitos dos quais se encontram amorfos e em desuso), com evidente valor simbólico e histórico (Figuras 6 e 7).

Pelo aplicativo, um sistema de pontuação poderia estimular as pessoas a se agruparem em ações de mutirão, intervirem e se apropriarem do espaço público. Esses pontos poderiam ser trocados como cupons de descontos nos estabelecimentos do bairro.

Figuras 6 e 7: Métodos de urbanismo tático em becos e travessas.

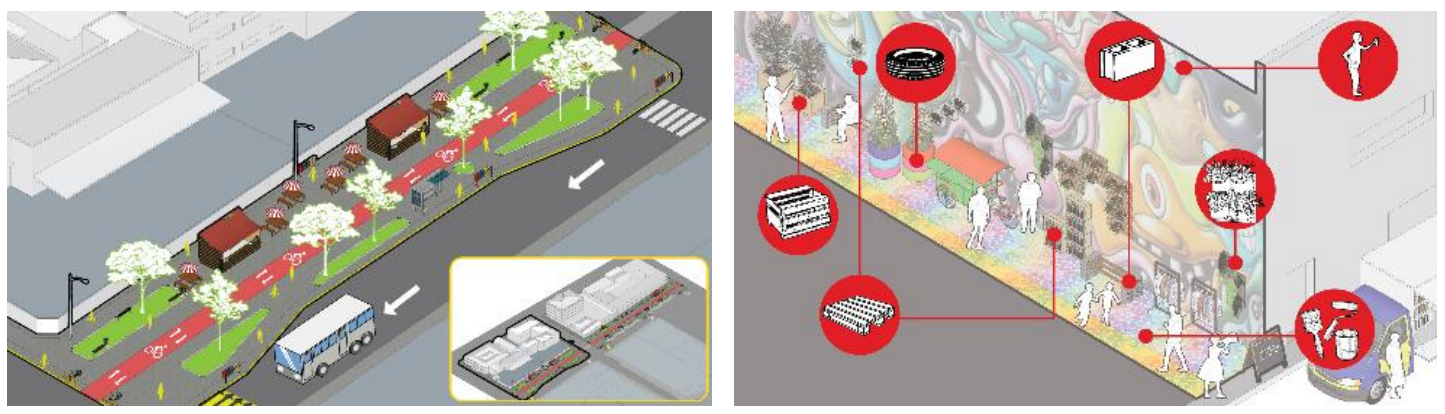

Fonte: Acervo dos autores (2018).

\subsection{AÇÕES NO ESPAÇO EDIFICADO}

Sobre os espaços edificados, o plano se detém nas edificações de valor patrimonial e nos imóveis que podem suportar maior potencial construtivo. No tocante às primeiras, que estão localizadas principalmente na Subzona de Comércio e Prestação de Serviços da ZEPH e na poligonal de tombamento do IPHAN, foram definidos alguns níveis de intervenção, observando o estado atual de preservação das mesmas, em diálogo com os critérios de proteção desses dois instrumentos de regulação (Figura 8).

Figura 8: Níveis de intervenção em edificações de valor patrimonial.

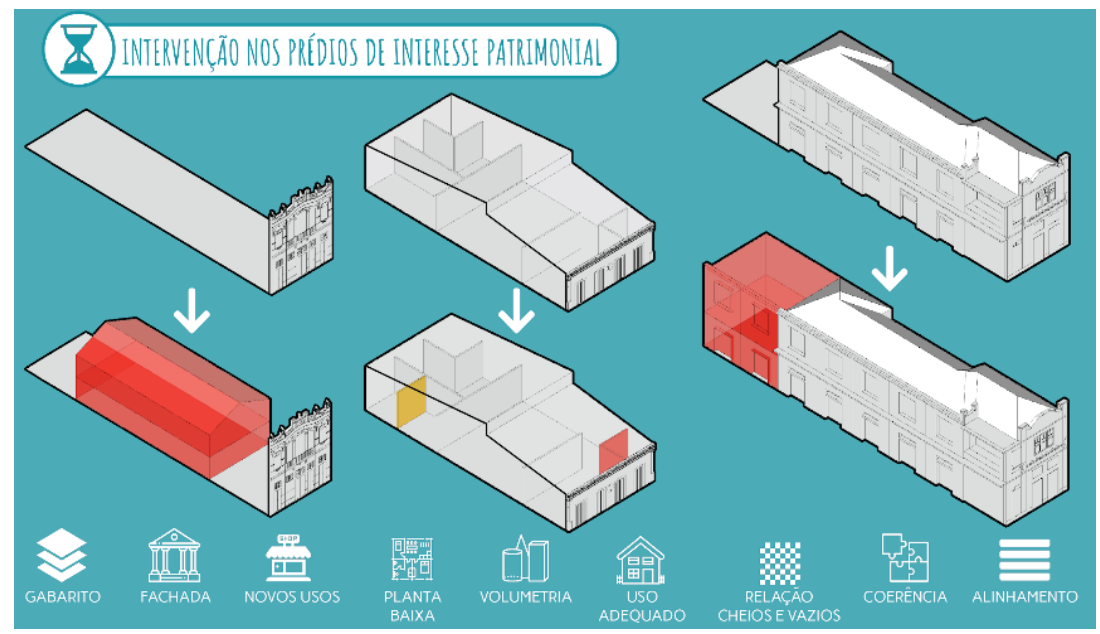

Fonte: Acervo dos autores (2018).

Destaque deve ser dado às edificações localizadas na rua Chile, que possuem papel fundamental no conjunto edilício de valor patrimonial do bairro, com maior concentração de ações de restauro das edificações subutilizadas ou abandonadas, que ainda mantém traços estilísticos passíveis de preservação, além de ser a via que permite a abertura das já mencionadas "janelas visuais" para o rio Potengi. Para a rua, o plano ainda indica, como iniciativa piloto, o aterro da fiação elétrica e a instalação de iluminação inteligente, com células fotovoltaicas e sensores de presença, de modo a valorizar o conjunto edificado ali existente.

Considerando o valor patrimonial das edificações existentes no perímetro histórico, indica-se ainda possibilidades de intervenção, cujos níveis variam de acordo com o estado de preservação e conservação dos imóveis. Os novos projetos devem respeitar as características do traçado e do conjunto edificado, sem recuo frontal, a relação de cheios e vazios e promover o diálogo entre as intervenções nos espaços externos 
e internos das edificações. Admite-se ainda possibilidades de remembramentos, para empreendimentos de maior porte, desde que seu uso seja coerente com a edificação.

Um exemplo de projetos para recuperação de prédios históricos a fim de os destinar a novos usos é o Projeto Ribeira Living Lab, uma proposta de incubadora de startups associada ao conceito de cidades inteligentes e humanas que almeja a transformação econômica, tecnológica e cultural do bairro. A proposta do Ribeira Living $L a b$, ora também em discussão nos espaços institucionais do município, representa uma possibilidade de fomentar novos usos para a área, respeitando suas características históricas e abrindo janelas para o Rio Potengi com a criação de um deck que se comunique com as demais edificações existentes (Figuras 9 e 10).

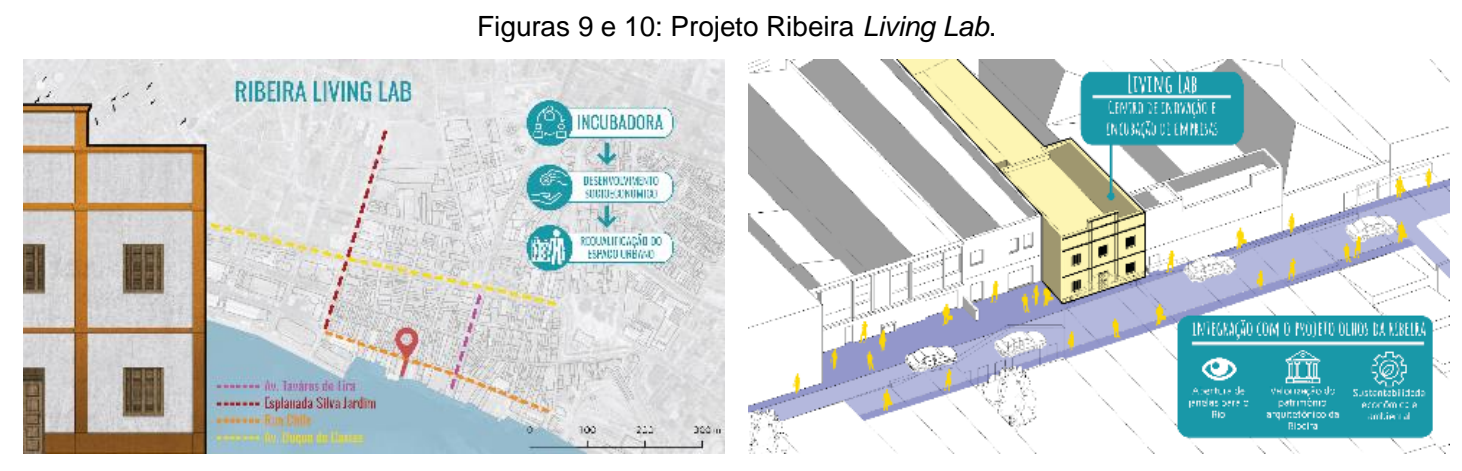

Fonte: Acervo dos autores (2018).

São propostos incentivos fiscais para o conjunto dos imóveis, como forma de estimular o uso misto das edificações e seu adensamento, incluindo o estímulo às atividades habitacionais, de modo a atrair moradores para a área. No contexto do estímulo à produção de moradias, também se propõe um edifício voltado para habitação de interesse social na modalidade incremental, que pode ser construído fora da poligonal de tombamento também protegida pelas regras urbanísticas.

\subsection{AÇÕES DE GESTÃO E PARTICIPAÇÃO SOCIAL}

Entre as possibilidades de implantação dos novos projetos a partir da aplicação dos instrumentos previstos no Estatuto das Cidades e no Plano Diretor em vigor, algumas relações previstas nas duas iniciativas anteriores de operações urbanas (1997 e 2007) para o bairro foram restabelecidas sob uma nova perspectiva.

Mantendo a ideia da operação urbana de 2007, propõe-se a criação de um fundo para receber os recursos a serem investidos em infraestrutura urbana, mobilidade e habitação social. Como forma de minimizar a centralização das ações, indica-se a utilização do financiamento colaborativo, tais como crowdfunding que incentivem a participação do pequeno investidor no bairro. Outras estratégias de financiamento incluem as contrapartidas do setor privado ou recursos arrecadados por agentes financiadores, como o BID e a Prefeitura de Natal.

Além disso, a fim de diversificar os usos, também propõe-se a aplicação de incentivos fiscais municipais, observando um zoneamento ajustado ao potencial de cada setor do bairro como: indústria criativa, turismo, pesca e comércio atacadista (Figura 11). Esses incentivos podem ser implementados através de uma nova operação urbana para a Ribeira. Estima-se ainda um cronograma preliminar de implementação, o número de unidades e o custo total para cada uma das fases do cronograma.

Os lotes e as edificações passíveis de intervenção foram classificados como fechados ou sem uso, públicos e privados, dentro e fora da poligonal de tombamento. Conforme consta na Figura 12, cada um desses lotes enquadra-se em determinado mecanismo de intervenção e financiamento, considerando o potencial construtivo do terreno e os custos aproximados da construção. Para os lotes e as edificações que estão sendo utilizados, são indicadas outras possibilidades de projetos, com estímulos à atividade residencial e a diversidade de usos no bairro. 
Figura 11: Zonas de Incentivos Fiscais

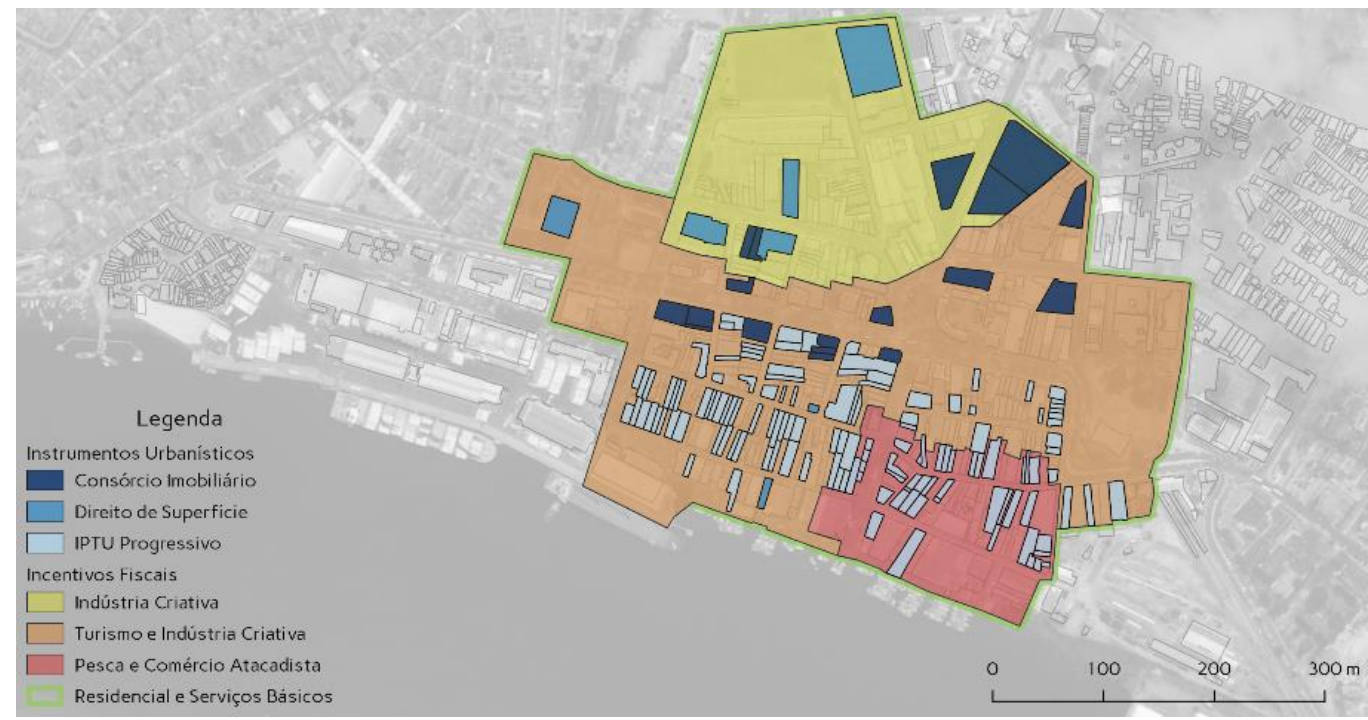

Fonte: Acervo dos autores (2018).

Figura 12: Diagrama dos modos de intervenção e implementação do projeto Olhos da Ribeira.

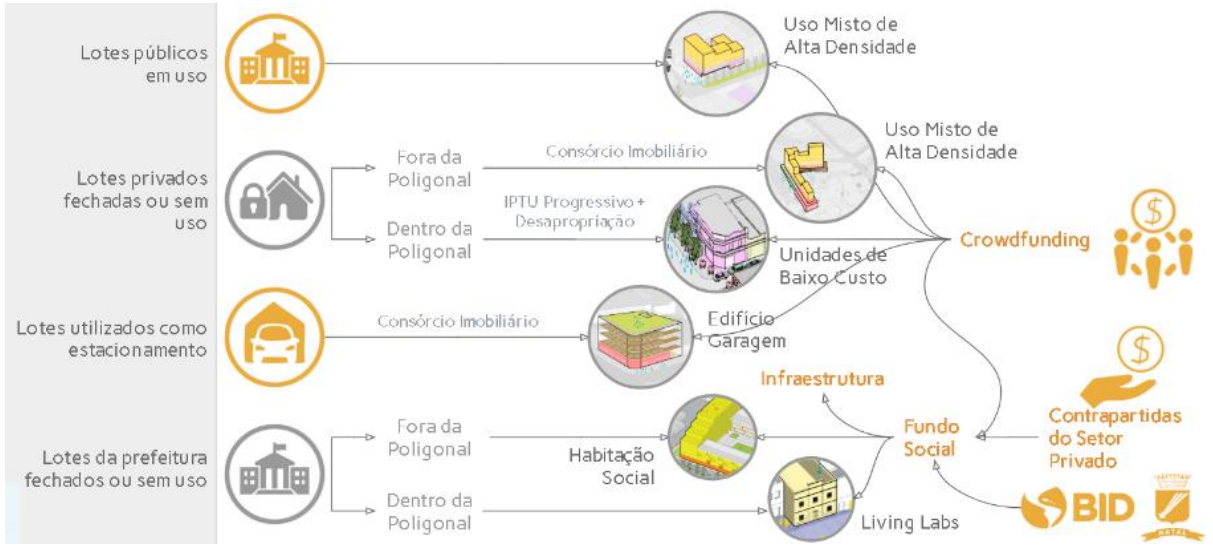

Fonte: Acervo dos autores (2018).

Todas essas ações podem ser acessíveis ao usuário e investidor do bairro por meio da plataforma participativa online referida. Com o aplicativo, qualquer cidadão pode: (1) doar para um determinado projeto em troca de recompensas ou (2) investir na Ribeira em troca de uma rentabilidade estimada. $\mathrm{O}$ usuário também poderá votar nas prioridades de investimentos do fundo social como uma rede de orçamento participativo online. Assim, o Projeto Olhos da Ribeira busca não apenas estabelecer diretrizes e parâmetros urbanísticos para o bairro, mas também realçar a necessidade do estabelecimento de um canal interativo de comunicação que articule Estado, mercado e população. Enfatiza-se a utilização do aplicativo como importante ferramenta para viabilizar essa proposta de forma interativa e participativa.

\section{CONSIDERAÇÕES FINAIS}

O projeto Olhos da Ribeira articula ações urbanísticas integradas a uma gestão participativa, a fim de resgatar a vitalidade que se arrefeceu no bairro Ribeira, além de propor novos usos e possibilidades de estratégias de economia colaborativa, indústria criativa, e inovações tecnológicas. O plano objetiva preservar o patrimônio arquitetônico e ressaltar o potencial urbanístico e paisagístico do bairro, articulando ações que orientam o restabelecimento da sua relação com o Rio Potengi e reafirmando as atividades que ainda resistem, como as pesqueiras e culturais. Além disso, propõe a instalação de novas atividades e usos, novos equipamentos e habitações.

Com base nos estudos realizados para elaboração do projeto, além das propostas físicas relacionadas aos projetos arquitetônicos e urbanísticos e dos instrumentos legais passíveis de implementação na área, foram 
propostos mecanismos de gestão com foco na participação social interativa como elemento inovador do projeto. A ideia do aplicativo nasce assim, para articular moradores, empreendedores e instituições interessadas no desenvolvimento da Ribeira. Mais que isso, esta ferramenta pode despertar nos moradores do bairro e da cidade de Natal o sentimento de identidade e pertencimento com o lugar.

Apesar das incertezas no que concerne ao futuro dos produtos revelados pelo concurso, esta iniciativa contribuiu para mobilizar a comunidade acadêmica, o poder público e outros segmentos sociais, despertando o interesse pelo debate sobre a necessidade de revitalizar o bairro. Os sucessivos encontros com os parceiros institucionais envolvidos com o projeto e uma parcela da sociedade civil fez a municipalidade voltar novamente seu olhar para a área, que também já foi alvo de diversas intervenções ao longo das três últimas décadas. Ainda que o projeto Olhos da Ribeira não se materialize, a equipe conseguiu cumprir um dos objetivos iniciais e que deu nome a proposta: abrir os olhos da cidade para a Ribeira. Espera-se que, dessa vez, tais olhos não voltem a se fechar.

\section{REFERÊNCIAS}

BRASIL. Lei n. 10.257 de 10 de julho de 2001. Regulamenta os artigos 182 e 183 da Constituição Federal, estabelece diretrizes gerais da política urbana e dá outras providências. Brasília: disponível em http://www.planalto.gov.br/ccivil 03/leis/LEIS 2001/L10257.htm, acesso 12 de fevereiro de 2018. .

MINISTÉRIO DAS CIDADES. Planejamento territorial urbano e política fundiária. Caderno do Ministério das Cidades, no 3, Brasília: MCidades/Governo Federal, 2004.

NATAL. Prefeitura Municipal do. Anuário Natal 2013. HORA, Carlos Eduardo Pereira da; MEDEIROS, Fernando Antonio Carneiro de; CAPISTRANO, Luciano Fábio Dantas (Orgs). Natal: SEMURB, 2013.

NATAL. Prefeitura Municipal do. Lei no 079, de 04 de janeiro de 2007. Dispõe sobre a Operação Urbana Ribeira, concede isenção e redução de tributos municipais e dá outras providências. Disponível em: http://www.natal.rn.gov.br/ anexos/publicacao/legislacao/leiComplementar 079.pdf, acesso em 20 de dezembro de 2017.

NATAL. Prefeitura Municipal do. Lei no 082, de 21 de junho de 2007. Dispõe sobre o Plano Diretor de Natal e dá outras providências. Disponível em: http://www.natal.rn.gov.br/semurb/paginas/File/.../24 Plano Diretor.pdf. Acesso em 20 de dezembro de 2017.

NATAL. Prefeitura Municipal do. Lei no 4.932, de 30 de dezembro de 1997. Dispõe sobre a Operação Urbana Ribeira e dá outras providências. Disponível em: http://www.natal.rn.gov.br/bvn/publicacoes/leste ribeira.pdf, acesso 15 de dezembro de 2017.

OLIVEIRA, Á.; SANTOS, I. Ribeira Living Lab: Proposta de Projeto da RIBEIRA VIVA. Natal: 2018. 53 p.

ROLNIK, R. A Construção de uma Política Fundiária de Planejamento para o País: Avanços e Desafios. Políticas Sociais (IPEA), v. 12, p. 199-210, 2006.

SEMURB- Secretaria de Meio Ambiente e Urbanismo -PMN.. Programa REHABITAR em Natal. Natal: Prefeitura Municipal do Natal, 2007.

SILVA, H. A. Revitalização Urbana de Centros Históricos: uma revisão de contextos e propostas - a Ribeira como estudo de caso. Dissertação (Mestrado em Arquitetura e Urbanismo) - Universidade Federal do Rio Grande do Norte, Natal, 2002.

TINOCO, M.; BENTES SOBRINHA, M. D. P.; TRIGUEIRO, E. B. F. (Orgs). Plano de Reabilitação de Áreas Urbanas Centrais - Ribeira. Natal,RN: EDUFRN, 2008.

\section{NOTAS}

${ }^{1}$ O coopere é um grupo de trabalho institucional para projetos estruturantes da ribeira e entorno que, sob a coordenação da Semurb, envolve diversas secretarias municipais e parceiros estaduais e federais.

NOTA DO EDITOR (*) O conteúdo do artigo e as imagens nele publicadas são de responsabilidade do(s) autor(es). 